\section{Estudo \\ Ecidebate}

em Cestã⿻

Planeiamento
Revista Estudo \& Debate, Lajeado, v. 27, n. 2, 2020. ISSN 1983-036X

DOI: http://dx.doi.org/10.22410/issn.1983-036X.v27i2a2020.2448

\title{
CORRUPÇÁO E ECONOMIA: UM ESTUDO SOBRE A CONVERGÊNCIA NO CONTEXTO MUNDIAL
}

\author{
Luis Felipe Guerini de Marchi', Gustavo Inácio de Moraes²
}

\begin{abstract}
Resumo: $\mathrm{O}$ presente trabalho tem como objetivo realizar uma análise sobre a convergência da percepção de corrupção nas economias mundiais, investigando as causas e os efeitos da corrupçâo na economia. O estudo motiva-se no fato de que a corrupção é um fator que altera de forma acentuada o cenário econômico e político dos países, afetando diretamente todas as pessoas que fazem parte de uma sociedade. Para isso é feita uma revisão e coleta dos dados fornecidos pelo Banco Mundial em parceria com a Transparência Internacional, através do ranking do índice de percepção de corrupção, desde 1995 até 2018. Feito isso, aplica-se os dados nas matrizes de transição com emprego das cadeias de Markov, para observar se existe uma convergência do índice e para quais grupos de classes dos países o índice está convergindo. Do mesmo modo, foram elaboradas classificaçóes acordo com o modelo, para formar as classes de grupos dos países. Como resultado, verifica-se uma convergência do índice de percepção de corrupção para as classes intermediárias, sendo este um resultado razoável/bom. Assim, observa-se uma dificuldade grande da maioria dos países para migrar para as classes superiores, sendo estas, as classes com os menores índices de corrupçáo.
\end{abstract}

Palavras-chave: Corrupção. Economias Internacional. Cadeia de Markov. Análise de Convergência. Índice de percepção.

\section{CORRUPTION AND ECONOMY: A STUDY ON CONVERGENCE IN WORLD CONTEXT}

\begin{abstract}
This paper aims to analyze the convergence of the perception of corruption across world economies, examining the causes and effects of corruption in the economy. The study is motivated by the fact that corruption is a factor that significantly changes the economic and political scenario of countries, directly affecting all people who are part of a society. To do this, we first review and collect data provided by the World Bank in partnership with Transparency International through the Corruption Perception Index ranking from 2011 to 2018. Once this is done, the data in the transition matrices is applied through of Markov chains, to see if there is a convergence of the index and to which country class groups the index is converging. Similarly, tables were prepared according to the general equilibrium model to form the group classes of countries. As a result, there is a convergence of the perception of corruption index for the intermediate classes, which is a reasonable / good result. Thus, it is very difficult for most countries to migrate to the upper classes, which are the classes with the lowest corruption rates.
\end{abstract}

1 Economista pela PUCRS.

2 Professor Adjunto do Programa de Pós-Graduaçáo em Economia da PUCRS. 
Keywords: Corruption. International Economy. Markov chain. Convergence analysis. Perception Indexes.

JEL Classification: C60, D73, F60, 050

\section{INTRODUÇÁO}

Em termos gerais, a corrupção é o abuso de poder confiado a alguém para obtenção de ganho privado. Pode ser classificada como grande corrupçáo, pequena corrupção e aquelas de natureza política ou privada (também conhecida como "corrupção comercial") a depender do volume de recursos apropriados indevidamente e do setor em que ocorre (TRANSPARÊNCIA INTERNACIONAL, 2018).

De acordo com a Transparência Internacional (2018), a grande corrupção se define pelos atos ilícitos praticados pelos governos, distorcendo políticas públicas e o funcionamento dos estados, permitindo benefícios aos líderes sobre os interesses públicos, juntamente com empresários de grandes empresas privadas, aumentando a desigualdade social e a ineficiência da economia.

A pequena corrupção corresponde aos abusos praticados pelos servidores públicos locais de baixo e médio escalão, nas suas interaçôes com as pessoas comuns. Segundo a Transparência Internacional (2018), esses atos acontecem frequentemente em hospitais públicos, escolas, delegacias de polícia e outras agências, de modo que o cidadão que se submeter a pagar o funcionário público, ganhará um tratamento diferenciado.

A corrupção é um dos maiores obstáculos ao desenvolvimento econômico e social do mundo, afetando de forma direta o bem-estar de todas as pessoas que fazem parte de uma sociedade. Corrupção está presente em todos os países do mundo, tanto no setor público quanto no setor privado, ocorrendo de diferentes formas e de diferentes intensidades, possuindo raízes profundas e se valendo de diversos condicionantes, desde aspectos institucionais e legais, até os comportamentais.

Segundo a Transparência Internacional (2018), um dos maiores problemas é de que os casos de corrupção impactam negativamente a credibilidade da democracia e geralmente estão relacionados à falta de transparência e ao nível de desigualdade social onde ocorrem.

A falta de transparência e o abuso de poder público pode ser identificado em diversos países em todos os continentes, frequentemente acompanhado de índices altos de desigualdade social, baixa credibilidade nos valores democráticos e violação de direitos humanos.

A corrupção no Brasil tem ganhado cada vez mais um papel de destaque no cotidiano e debates entre os brasileiros, seja por estudos cada vez mais aprofundados sobre o caso, seja por noticiários divulgados seguidamente pela mídia nacional, ou principalmente pelo momento político que o país vive.

Corrupção no mundo, e principalmente no Brasil não é algo novo, porém, nos últimos seis anos tem se tornado cada vez mais parte da vida de todos os brasileiros, pelo fato de que seguidamente torna-se público escândalos cada vez maiores e mais engenhosos, fomentando cada vez mais essa prática que destrói o país e o desvia de suas diretrizes. 
O objetivo principal desse estudo é analisar se existe convergência de corrupção nas economias mundiais medida e avaliada pela percepção do índice da Transparência Mundial. Assim, a pergunta principal é: estariam as economias convergindo para um padrão único de corrupção? Se sim, qual seria esse nível? A hipótese principal é que a maior difusão do capital e empresas ao redor do mundo e o maior grau de abertura de comércio estabeleceriam uma convergência ao longo do período de análise.

Consequências do ponto de vista macroeconômico de como a corrupção pode ser vista como um imposto, um custo adicional para a obtenção de um serviço público, de um produto ou de um favor que modifica a alocação eficiente dos recursos.

O presente estudo está dividido em cinco seções, incluindo esta introdução. A segunda seção fará uma revisão da literatura, analisando a economia da corrupção, abordando seus aspectos e suas visóes institucionais, sociológicas e econômicas, desenvolvendo o histórico da corrupção no Brasil e fora do país também. A terceira seção aborda a metodologia, utilizando a cadeia de Markov e suas matrizes para analisar a convergência da corrupçáo nos 171 países que fazem parte da pesquisa e que compóem o Índice de Percepção de Corrupção (IPC) do Banco Mundial. Na quarta seção apresentam-se os resultados e discussóes. E por fim, a quinta e última seção apresenta as conclusôes sobre os resultados obtidos durante o estudo.

\section{ECONOMIA DA CORRUPÇÁO}

Segundo Fonseca (2011), a corrupção é objeto de estudo em diversas áreas do conhecimento. Filosofia, sociologia, direito, ciência política e principalmente economia procuram compreender o fenômeno e projetam soluçóes para o problema. As ciências mencionadas acima, não conseguem prever seus verdadeiros efeitos, visto que não observam os incentivos criados pela corrupção, e é exatamente como a economia trata do fenômeno, como um problema de incentivos, utilizando suas ferramentas teóricas e analíticas para testar suas hipóteses e esclarecer os problemas.

Para Fernandes (2017), os esforços bem-sucedidos de combate à corrupção são muitas vezes liderados por uma "coalizão de interessados" - por políticos e altos funcionários do governo, pelo setor privado e cidadáos, comunidades e organizaçóes da sociedade civil.

Corrupção é um problema global e, que, apesar de não ser novo na dinâmica política e econômica, ganha destaque nos últimos anos, tanto nos aspectos políticos e sociais, quanto ao seu impacto econômico (CARRARO; HILLBRECHT, 2003).

A corrupção não é um problema uniforme e autônomo. Em vez disso, é um sintoma de que as relaçôes entre estado e sociedade operam de maneira que prejudicam a justiça e a legitimidade do estado e que levam ao desperdício e à fraca orientação dos gastos públicos. A corrupção ocorre dentro de uma estrutura onde as leis e os regulamentos básicos estão em vigor, e os executivos aproveitam oportunidades para se beneficiarem (FERNANDES, 2017).

Ainda segundo Abramo (2000), as recentes tentativas de compreensão sobre a corrupção vão da interpretação superficial dos escândalos mais recentes até a avaliação detalhada das falhas individuais e estruturais que propiciam determinados esquemas. Durante 
muito tempo, análises qualitativas não foram implementadas por uma medição empírica da ocorrência, desde a simples questão do grau de corrupção em países ou instituiçôes até as questóes com um grau de complexidade maior sobre as relaçóes causais entre corrupçáo, cultura política, desenvolvimento e o perfil das instituiçóes políticas administrativas.

Nesse sentido, a relação entre a corrupção e a economia subterrânea (atos econômicos ilícitos) tem um elo muito conectado. A corrupção e a economia subterrânea reforçam-se juntamente por conta da baixa qualidade institucional, e associadas a menores níveis de desenvolvimento. Como o elo entre as duas variáveis é fortemente conectado, combater a corrupção é combater a economia subterrânea. Para esse combate ser eficaz e apresentar resultados significativos, o esforço para combater deve ser em grande parte direcionado para a melhoria institucional, pois é por meio da qualidade institucional que políticas fiscais e públicas serão significativas (KLEIN, 2008).

A partir do estudo de Rose-Ackerman (1975), foram criados modelos econômicos que permitiram explicar a corrupção pelo ponto de vista econômico, e através de Mauro (1995) que foi o pioneiro utilizando a análise de cross-section para estimar os efeitos da corrupção no crescimento econômico. A partir desses, se possibilitou concluir pesquisas semelhantes em torno da corrupção com outros indicadores econômicos, Tanzi e Davoodi (1997) analisaram o comportamento do investimento público diante da corrupção, e AlMarhubi (2000) usou a inflação para sua análise.

De acordo com Garcia (2003), no que diz respeito a parte econômica, os estudos sobre a corrupção possuem uma abordagem microeconômica e uma abordagem macroeconômica. A abordagem que envolve a parte microeconômica sobre o assunto, verifica se existe ou não, corrupção a partir dos modelos de comportamentos que maximizam a utilidade. $\mathrm{E}$ a abordagem macroeconômica busca estimar variáveis, coletando as taxas de crescimento econômico e investimento; a entrada de capital externo; a qualidade da infraestrutura do país e a relação da corrupção com a taxa de inflação.

O estudo de Rose-Ackerman (1975), foi baseado no modelo de economia do crime de Gary Becker (1968), sendo considera o pioneiro no estudo da corrupção. O modelo analisa as condutas corruptas de acordo com seus custos e ganhos, ou seja, o indivíduo somente se corromperia se o benefício de seus atos fosse maior que o valor esperado de ser descoberto e punido. Assim como o de Becker (1968), o corrupto de Rose-Ackerman (1975) age racionalmente de acordo com a possibilidade de ganho e a possibilidade de ser pego.

No estudo de Schleifer e Vishny (1993), os autores atribuem a corrupção à estrutura de mercado dos bens públicos. Os burocratas respondem aos mesmos incentivos de produtores de outros bens públicos disponíveis no mercado. Uma vez que possuem o monopólio dos bens públicos, eles impóem barreiras a oferta para conseguirem propinas dos demandantes, sendo esta, a mesma lógica do mercado, onde diminuindo a oferta, o preço aumenta, porém, neste caso, a diferença do preço fica toda com os burocratas. Essa abordagem é considerada como a Organizaçâo Industrial (OI) de corrupção.

De acordo com Speck (2000), as tentativas mais comuns de quantificação se baseiam em três diferentes indicadores: os escândalos relatados na mídia, as condenaçóes 
contabilizadas nas instituições ligadas à esfera penal e as informações obtidas em pesquisas entre cidadãos.

Uma das vertentes teóricas comumente utilizadas para explicar a origem da corrupção é a teoria dos caçadores de renda (rent-seeking). De acordo com essa visão, os agentes econômicos visam maximizar seu bem-estar econômico, sujeitos a um determinado conjunto de leis e regras. A diferença entre um agente caçador de renda e corruptos e corruptores está no fato de que estes últimos agem fora da lei. Assim, a corrupção seria maior em sociedades com excesso de regulamentação sobre o mercado, onde predomina a impunidade, e onde haja maior tolerância ao fenômeno (SILVA, 2001).

Segundo Mauro (1997), além da má alocação dos recursos, a corrupção ajuda a distorcer a alocação de talentos. A atividade de rent-seeking chama a atenção de pessoas bem-educadas e talentosas, por ser uma atividade altamente lucrativa. A busca da melhor remuneração acaba por deixar deficiente a oferta de trabalhadores habilidosos para as áreas produtivas, tornando menor a oferta de capital humano a ser utilizada no crescimento econômico.

Para a corrente rent-seeking, ressalta-se a impossibilidade do desenvolvimento sem a participação do Estado. Isso acontece porque o crescimento econômico que o acompanha tende a efetuar-se com profundos desequilíbrios sociais e regionais. Entretanto, o crescimento das funçóes do governo eleva os gastos públicos e o excesso de regulamentação acaba provocando perda de eficiência gerando corrupção, que privilegia determinados grupos, em detrimento do conjunto da sociedade levando a consequentes custos, tanto privados quanto sociais (SOUZA, 2005).

Carraro e Damé (2007), analisam que trazendo essa ideia na argumentação econômica, considera-se que o aumento do nível de educação da população em geral faria com que as pessoas fiscalizassem mais as açóes na administração pública, impedindo atos corruptos. De acordo com os autores, é mais difícil enganar um povo mais bem instruído que está por dentro do processo democrático e institucional, além de que educação traz consigo noçóes de ética, que é fundamental no combate a corrupção, Porém, surpreendentemente, os resultados da pesquisa indicam que ao aumentar a expectativa dos anos de escolaridade e do número de inscritos no ensino superior, a corrupção também se eleva, e para os referidos autores, a corrupção será maior nos países que possuem instituiçóes mais burocráticas.

Mauro (1995) evidencia que um dos grandes malefícios trazidos pela corrupção é a má alocação de talentos, onde indivíduos instruídos seriam incentivados financeiramente a realizar atividades de rent-seeking ao invés de praticar trabalhos produtivos. Dessa maneira, o simples aumento do nível geral de educação elevaria as atividades de rent-seeking, fortalecendo a existência de corrupção ao gerar as oportunidades necessárias.

A relação entre sociedade e Estado não está isenta das atividades ilícitas. Em países onde existem muitas regulamentaçóes governamentais e várias etapas complexas para a realização de atividades comerciais, há fortes evidências da existência de corrupção de agentes públicos, Mauro (1995), e onde determinados grupos buscam atender seus interesses privados através da corrupção de agentes ou instituiçóes públicas (ROSE-ACKERMAN, 1996). 
A corrupção burocrática se faz presente à medida que um burocrata possui o poder de alocar a oferta de um bem ou serviço público. Ao perceber ser monopolista da oferta e de possuir o poder discricionário para definir quem receberá ou não o bem público, esse burocrata racionalmente decide vender o bem público, demandando uma propina. Esse tipo de corrupção tem sua explicação teórica mais associada à estrutura de mercado do governo (SHLEIFER; VISHNY, 1993), pois o monopólio e o poder discricionário geram os incentivos e as oportunidades para o burocrata decidir racionalmente ser corrupto.

A corrupção não é só um problema político ou moral, mas um problema econômico também. A prática ilícita acontece em governos, de países ricos e pobres, grandes ou pequenos, de política liberal ou conservadora, afetando negativamente o crescimento econômico em diferentes intensidades, (Carraro; Fochezatto; Hillbrecht. 2006).

A corrupção possui caráter tanto público quanto privado, sendo o Estado e o mercado vetores interligados na sua prática (MAURO, 1995).

A corrupção política baseada nos estudos da Teoria da Escolha Pública (BUCHANAN; TULLOCK, 1962). Um dos pressupostos é que o desempenho econômico das empresas e o desempenho político dos candidatos estáo interligados pelo processo eleitoral (PERSSON; TABELLINI, 2003). Assim, políticos e empresários são tratados como agentes maximizadores de interesses próprios que se encontram no mercado político para atender às suas necessidades. De um lado, há políticos em campanha que necessitam de recursos financeiros para maximizar a probabilidade de serem eleitos, e de outro, empresários desejam maximizar seus lucros por meio da atuação de políticos eleitos que realizam políticas públicas em prol de seus objetivos (MITCHELL; SIMMONS, 2003).

A visão anglo-saxônica observa a corrupção como um modelo diferente, constituído na relação principal-agente, que consiste em uma relação formada por três pessoas: o principal, sendo esse o que estabelece a relaçáo com o agente, o qual passa a atuar em sua representação, e o outro, que oferece vantagens ao agente para que traia o principal, através da quebra de deveres referentes a sua posição de representante.

O esquema apresentado se diferencia dos outros conceitos antes feitos pelo fato de possibilitar explicar a corrupçáo nos setores público e privado. A luz do esquema anglosaxônico, De La Torre e Cerina (2011), complementam que "no caso do setor público, a administração atua como o principal do servidor público. Em função de uma relação que poderíamos chamar de agência, o servidor público ganha uma posição qualificada por meio da qual, em troca da concessáo de certos poderes, encontra-se vinculado a atuar no interesse do principal (administraçáa) e a fazê-lo respeitando certas regras."

Corrupçáo privada são determinadas práticas de deslealdade concorrencial. Entre empresas, se dá em razão da vantagem deslealmente proporcionada a um concorrente do empregador por um funcionário que náo cumpre seus deveres de empregado, e possui o intuito de obter determinados proveitos. No mesmo esquema apresentado por De La Torre e Cerina (2011), agora direcionado para o setor privado, ou centro de interesses (geralmente uma empresa), dá a permissão a um agente (geralmente um empregado), o poder de atuar em nome dela. Para tal, o agente deverá saber as regras direcionadas a sujeitos que operam no mercado, sejam elas internas (regulamento interno ou código de ética da empresa) ou 
externo, lei aprovada pelo congresso. Do mesmo modo do setor público, o outro será o responsável por oferecer as vantagens ao agente, para que ele quebre seus deveres de função e realize determinadas açóes do interesse desse terceiro, em prejuízo do principal.

No mundo globalizado, onde as atividades econômicas estáo conectadas em uma rede de correlação mercadológica, é de extrema importância a criação de uma política criminal atuante, e que de acordo com Chaves (2014), atos de deslealdade concorrencial serem severamente punidos em um país, e simplesmente, não configurarem crimes em outros, desequilibra as relaçóes econômicas estabelecidas na esfera transacional.

Para Baungarten, Orellana e Menezes (2016), o aumento da democracia nos países pode ter aberto uma possibilidade de maiores discussóes sobre a questão da corrupçáo, bem como o papel de destaque das organizaçóes internacionais, como a mídia impulsionada pelo processo de globalização, auxiliando na divulgação das notícias relacionadas a temática, assim como o aumento da consciência sobre o problema.

Para Carraro, Fochezatto e Hillbrecht (2006), a corrupção é tratada como um problema de políticas econômicas, sendo elas neutras e trazendo benefícios e custos, alterando os preços relativos, modificando ganhos e modificando também a forma como os agentes racionais e maximizadores de renda se comportam. Consequências do ponto de vista microeconômico a corrupção pode ser vista como um imposto, um custo adicional que deve ser envolvido para a obtençấo de um serviço público, de um produto ou de um favor que modifica a alocação eficiente dos recursos. Em um mercado competitivo a remuneraçáo dos fatores de produção depende da sua produtividade. Carraro, Fochezatto e Hillbrecht (2006), afirmam que alocaçōes corruptas devem gerar alocaçóes ineficientes dos recursos, diminuindo a produtividade dos fatores e as suas remuneraçóes. Com menor remuneração as famílias podem decidir poupar menos, afetando investimento e poupança. Menor remuneração do capital pode afastar investidores que deslocarão seu capital para países com menor corrupção, afetando todo o sistema econômico. Nos estudos de Tanzi (1994) e Buchanan e Tullock (1980), os resultados comprovam que existe uma relação positiva entre tamanho do Estado e corrupção.

A corrupção reduz as receitas e aumenta o gasto público, contribuindo para a geração de déficits fiscais, que podem ter consequências inflacionárias. A corrupção presente na economia pode também desestimular o investidor privado a realizar novos investimentos, pois além de elevar o custo do investimento, aumenta as incertezas sobre ele mesmo (MAURO, 1995).

No estudo de Mo (2000), o autor mensura o impacto da corrupçáo no crescimento econômico e investiga também que os canais de transmissão que mais propagam a corrupção são: o de capital humano, pelo fato de que a corrupção reduz o estoque do mesmo no país, concluindo que os recursos fluam das atividades produtivas para as náo produtivas (rent-seeking); o de investimento, concluindo que a taxa de crescimento do PIB depende da taxa de investimento, e a corrupção diminui a abertura de novos investimentos pelo agente corrupto atravancar em um maior grau o sistema, para obter maiores ganhos; e a estabilidade política, concluindo que existe uma relaçáo positiva entre desigualdade de renda e a instabilidade sociopolítica. 
Para Lambsdorff (1999), a qualidade institucional é a principal atividade no combate a corrupção, de modo que a existência de instituições confiáveis, sólidas e transparentes desestimulam a corrupção, ou ainda um baixo nível de corrupção incentivaria a existência de um meio institucional transparente.

A corrupção também possui correlação com a desigualdade. Gupta, Davoodi e Alonso-Terme (1998), utilizando o coeficiente de GINI como medida de desigualdade, chegam à conclusão de que a corrupção aumenta a desigualdade e a pobreza através do seu impacto sobre o crescimento econômico. Os autores ressaltam que países em situaçóes desiguais e de pobreza apresentam uma maior dificuldade de enfrentar o problema da corrupção, o que cria um ciclo ainda mais difícil de ser quebrado.

De acordo com Mauro (1995) e Tanzi (1998), existe uma relação da corrupção com o nível de investimento dos países, assim como para outras variáveis econômicas, como o Produto Interno Bruto per capita (PIB per capita), uma relaçáo negativa é encontrada nesses trabalhos de modo que a corrupção pode influenciar negativamente a geração de riqueza dos países, contribuindo para um baixo nível de desenvolvimento, pobreza e desigualdade.

Segundo Abramo (2005), se a corrupção é importante economicamente, então se torna importante medi-la, porém, trazendo um problema de imediato. Como os atos de corrupção são secretos, e não se sabe ao certo o volume das transaçóes ilícitas, medidas diretas estão fora de questão, sendo assim, medidas indiretas estão no controle.

\section{METODOLOGIA}

O presente capítulo usará os processos da Cadeia de Markov, na aplicação dos dados que serão analisados, dados esses retirados do índice de corrupção do Banco Mundial.

Um processo estocástico é uma regra que mostra a probabilidade com que o sistema, ou um indivíduo, desse sistema estará no estado $i$ no período $n+1$, sabendo as probabilidades com que esteve nos vários estados em períodos anteriores. Essa probabilidade poderia, em princípio, depender de toda a história prévia do sistema, ou seja, dos estados que existiam nos tempos $1,2, \ldots, \mathrm{n}$.

Um processo estocástico é determinado Matriz de Markov se a probabilidade com que o sistema está no estado $i$ no período $n+1$ depende somente do estado que o sistema esteve no período $n$. Para processos de Markov, só interessa o passado imediato (SIMON e BLUME, 2004).

Os principais elementos que compóem um processo de uma Matriz de Markov são:

- A probabilidade $x^{i}(n)$ de ocorrer o estado $i$ no $n$-ésimo período de tempo, ou alternativamente, a fração da população em questão que está no estado $i$ no n-ésimo período de tempo.

- As probabilidades de transição $m_{i j}$, ou seja, as probabilidades com que o processo estará no estado $i$ no tempo $n+1$ se estiver no estado $j$ no tempo $n$.

É natural agrupar as probabilidades de transição em uma matriz, denominada Matriz de Markov: (SIMON e BLUME, 2004). 
Um dos exemplos mais clássicos de aplicabilidade das Cadeias de Markov é a teoria dos jogos, que se prova de forma bastante simples o problema da ruina do jogador. Outro ramo muito abordado em cadeias de Markov é a teoria das filas, na qual pretende modelar matematicamente o comportamento de uma fila a fim de satisfazer da melhor forma possível o cliente (usuário da fila), e que também seja economicamente viável ao prestador de serviços. Na mesma linha, a cadeia de Markov se aplica para teorias em processos de difusão de informação, migratórios, epidemiológicos etc. (FERNANDES e VARGAS, 2006).

Uma cadeia de Markov de tempo discreto é um processo estocástico de tempo discreto que apresenta a propriedade de Markov. A definição desta propriedade, também chamada de memória markoviana, é que os estados anteriores são irrelevantes para a predição dos estados seguintes, desde que o estado atual seja conhecido. Existem também cadeias de Markov de estado contínuo. Uma cadeia de Markov é uma seqüencia $X_{1}, X_{2}, X_{3}, \ldots$ de variáveis aleatórias. $\mathrm{O}$ alvo destas variáveis, isto é, o conjunto de valores que elas podem assumir, é chamado de espaço de estados, onde $X_{n}$ denota o estado do processo no tempo $\mathrm{n}$ (FERNANDES e VARGAS, 2006).

Se a distribuição de probabilidade condicional de $X_{n}+1$ nos estados passados é uma função apenas de $X_{n}$, então:

$\operatorname{Pr}\left(X_{n+1}=i X_{0}, X_{1}, X_{2}, \ldots, X_{n}\right)=\operatorname{Pr}\left(X_{n+1}=i X_{n}\right)$, onde x é um estado do processo.

A identidade acima define a propriedade de Markov.

\section{1 Índice de Percepção de Corrupção (IPC)}

A aparição do Índice de Percepção de Corrupção (IPC) avaliado pela Transparência Internacional, no início dos anos 1990, alterou significativamente a forma de avaliação da corrupção entre países. A disponibilidade de um índice padrão com uma nota quantitativa para a existência de corrupção, para uma amostra grande de países, permitiu a ampliação de trabalhos empíricos de estimação das causas e das consequências da corrupção usando estimativas econométricas do tipo cross-section e de dados de painel, analisados por Mauro (1997), Treisman (2000), Anderson e Tverdova (2003) e Tanzi e Davoodi (1997). A partir dessas metodologias, o problema da corrupção se tornou popular, amplamente discutido no meio político e serviu de base para diversos programas de combate a esse problema.

A Transparência Internacional (TI), que é a mais importante organização não governamental do mundo no combate a corrupçáo, apresenta anualmente o índice de percepção de corrupção (IPC), que mede o grau de corrupção em um país e avalia se ele está melhorando ou piorando a sua colocação no ranking de acordo com seus indicadores.

Para um país aparecer no ranking, ele precisa ser avaliado no mínimo por três indicadores globais usados pela TI. No último ano o Brasil teve seus dados analisados pelos seguintes indicadores: Avaliação Institucional e Política de País do Banco Mundial (2017); Pesquisa de Opiniáo Executiva do Fórum Econômico Mundial (2017); Guia de Risco Internacional do Grupo PRS (2017); e Avaliação Global de Risco do País (2017).

Em uma escala que vai de 0 (mais corrupto) a 100 (menos corrupto), são avaliados 180 países do mundo inteiro. A TI realiza as pesquisas qualitativas, e as converte em 
várias escalas quantitativas. A partir disso, a ONG combina os resultados dessas pesquisas, converte seus valores na escala de 0 a 100, e assim, consegue calcular uma média para cada país (TRANSPARENCY INTERNATIONAL, 2017).

\section{RESULTADOS}

Desenvolvendo uma série de trabalhos, Quah (1993) levantou argumentos em prol das ideias de catch-up e de pushing back, até então inexplorados na análise de convergência, e utilizando métodos não paramétricos e matrizes de transição de Markov, identificando as probabilidades de uma determinada economia melhorar sua posição relativa quanto a um grupo de economias.

Quah (1993) descreve uma estratégia simples, que analisa a taxa de crescimento médio, onde as variáveis de cross-section variam ou se correlacionam com as variáveis explicativas. Apresenta-se também que se ajustem individualmente os dados de cada país a um processo autorregressivo de tendência linear, usando Mínimos Quadrados Corrigidos (MQC), analisando a cada caso o comportamento de tendência.

Em seu estudo, Stulp e Fochezatto (2004) indicam que a utilização do método de matriz de Markov, para análise de convergência, consiste em definir os estados da natureza como intervalos de classes padronizados pela média da distribuição da variável que está sendo analisada, de tal forma que se pode construir uma matriz de probabilidades de transição entre essas classes de renda, para só então, poder analisar a convergência.

Desse modo, a cada período que se sucede, os países podem migrar para um estrato diferente, com uma determinada probabilidade definida na matriz de transição. É possível também, estimar a probabilidade de ocorrência de um determinado evento em um possível futuro, o qual só depende da distribuição no período presente e da matriz de transição.

No presente estudo, utiliza-se a metodologia de cadeias de Markov em um processo estacionário de primeira ordem, descrita por Quah (1993).

Com o propósito de investigar a convergência do Índice de Percepção de Corrupção (IPC), utilizou-se o maior número de países, no qual, se incluem 171 países com características distintas entre si. São analisados países desenvolvidos e países em desenvolvimento que compóem o grupo dos países com a disponibilidade dos dados sobre corrupção, medidos e fornecidos pelo Banco Mundial, analisados de 2011 a 2018.

A aplicação do processo estacionário de primeira ordem de cadeias de Markov requer uma matriz de probabilidade de transição, onde se propóe que, dado o intervalo de classes h, seja possível determinar o número de estratos ou classes em que se posicionam os países. Observando os países, pode-se analisar quantos países permaneceram na mesma classe e quantos trocaram de classes no período analisado.

A abordagem da matriz de Markov consiste em um processo estocástico onde as observaçóes são feitas em tempo discreto e são chamadas de modelos de migração pelo fato do país migrar de uma classe para a outra, dependendo apenas do estado em que o país se encontra no presente e no instante futuro, e não pelo seu histórico de mudança que teve anteriormente. 
Como primeiro passo, encontrou-se o intervalo de classe, que é igual a 0,171. Formaram-se as classes começando no valor do índice IPC mediano igual a 0,39

O intervalo de classes $h$ foi estimado de acordo com a fórmula

$$
h=2,72 \sin ^{1 / 3}
$$

sendo $s$ o desvio padrão da distribuição e $n$ o número de observaçóes. $\mathrm{O}$ número de observaçóes em cada ano é 171. O desvio padrão dos índices referentes ao ano de 2011 é igual a 0,212485 e o dos índices referentes a 2018 é 0,194084 . Obteve-se um $h$ igual a 0,104306 para o ano de 2011, e igual a 0,095273 para o ano de 2018. Utilizou-se o $h$ médio aproximado de 0,171 para cada um desses dois anos. Os intervalos de classe foram calculados a partir do valor mediano de IPC 0,37. Desse modo, os países foram classificados em cada ano, em oito classes de índices, conforme a tabela 1.

Tabela 1 - Intervalo das oito classes de níveis de IPC.

\begin{tabular}{|c|c|}
\hline Classe & Valor do índice de IPC \\
\hline 8 & Acima de 0,79 até 0,88 \\
\hline 7 & Acima de 0,7 até 0,78 \\
\hline 6 & Acima de 0,6 até 0,69 \\
\hline 5 & Acima de 0,49 até 0,59 \\
\hline 4 & Acima de 0,39 até 0,48 \\
\hline 3 & Acima de 0,29 até 0,38 \\
\hline 2 & Acima de 0,19 até 0,28 \\
\hline 1 & Acima de 0 até 0,18 \\
\hline
\end{tabular}

Fonte: Elaborada pelo autor.

Analisou-se a migração dos países de uma classe para a outra ou se permaneceram na mesma classe, nos anos de 2011 a 2018. Essa migração originou um sistema de equaçóes de diferenças, sendo Ft e Ft+1 as distribuições dos países, respectivamente, no tempo $t$ (2011) e $t+1$ (2018), e através da matriz de transição de Markov, foi possível construir um sistema de equaçóes que expressa a evolução da distribuição dos países entre classes de IPC, ao longo do tempo, e tal sistema é representado por:

$$
F t+1=M F t
$$

onde $M$ é a matriz de transição de Markov, e indica a probabilidade de cada país da classe $i$ de IPC no tempo $t$ estar na classe $j$ no tempo $t+1$. A hipótese básica associada a esse procedimento é a de que as probabilidades de transição sejam estacionárias, ou seja, a probabilidade de passagem de uma classe para a outra seja invariável no tempo. 
Tabela 2 - Número de países nas classes de níveis de IPC em 2011 e 2018.

\begin{tabular}{c|ccccccccc}
\hline Classes em 2018 & \multicolumn{10}{c}{ Classes em 2011 } & Total de países em \\
\cline { 2 - 8 } & $\mathbf{1}$ & $\mathbf{2}$ & $\mathbf{3}$ & $\mathbf{4}$ & $\mathbf{5}$ & $\mathbf{6}$ & $\mathbf{7}$ & $\mathbf{8}$ & $\mathbf{2 0 1 8}$ \\
\hline $\mathbf{1}$ & 6 & 6 & 0 & 0 & 0 & 0 & 0 & 0 & 12 \\
$\mathbf{2}$ & 2 & 24 & 4 & 0 & 0 & 0 & 0 & 0 & 30 \\
$\mathbf{3}$ & 1 & 19 & 25 & 1 & 1 & 0 & 0 & 0 & 47 \\
$\mathbf{4}$ & 0 & 0 & 18 & 9 & 0 & 0 & 0 & 0 & 27 \\
$\mathbf{5}$ & 0 & 0 & 0 & 11 & 5 & 2 & 0 & 0 & 18 \\
$\mathbf{6}$ & 0 & 0 & 0 & 1 & 5 & 3 & 4 & 0 & 13 \\
$\mathbf{7}$ & 0 & 0 & 0 & 0 & 0 & 2 & 6 & 4 & 12 \\
$\mathbf{8}$ & 0 & 0 & 0 & 0 & 0 & 0 & 1 & 11 & 12 \\
\hline Total de paises & $\mathbf{9}$ & $\mathbf{4 9}$ & $\mathbf{4 7}$ & $\mathbf{2 2}$ & $\mathbf{1 1}$ & $\mathbf{7}$ & $\mathbf{1 1}$ & $\mathbf{1 5}$ & $\mathbf{1 7 1}$ \\
em 2011 & & & & & & & & & \\
\hline
\end{tabular}

Fonte: Elaborada pelo autor.

Com base nos valores da tabela acima, determinam-se a matriz de Markov e o sistema de equaçóes de diferenças correspondentes aos dados que são:

Figura 1 - Matriz de Markov e sistema de equaçóes de diferenças correspondentes.

\begin{tabular}{|c|c|c|c|c|c|c|c|c|}
\hline & 1 & 2 & 3 & 4 & 5 & 6 & 7 & 8 \\
\hline $\mathrm{F} 1_{t+1}$ & 0,667 & 0,125 & 0 & 0 & 0 & 0 & 0 & 0 \\
\hline $\mathrm{F} 2 t+1$ & 0,222 & 0,489 & 0,085 & 0 & 0 & 0 & 0 & 0 \\
\hline $\mathrm{F} 3 t+1$ & 0,111 & 0,387 & 0,532 & 0,045 & 0,090 & 0 & 0 & 0 \\
\hline $\mathrm{F} 4 t+1$ & 0 & 0 & 0,382 & 0,409 & 0 & 0 & 0 & 0 \\
\hline $\mathrm{F} 5 t+1$ & 5 & 0 & 0 & 0,500 & 0,454 & 0,285 & 0 & 0 \\
\hline $\mathrm{F} 6 \mathrm{t}+1$ & 0 & 0 & 0 & 0,045 & 0,454 & 0,428 & 0,363 & 0 \\
\hline $\mathrm{F} 7 t_{t+1}$ & 0 & 0 & 0 & 0 & 0 & 0,285 & 0,545 & 0,267 \\
\hline $\mathrm{F} 8 t+1$ & 0 & 0 & 0 & 0 & 0 & 0 & 0,090 & 0,733 \\
\hline
\end{tabular}

Fonte: Elaborada pelo autor.

A distribuição de probabilidades do início do período (quando $t=0$, ou seja, em 2011), apresenta os seguintes valores: 
Figura 2 - Distribuição de probabilidades no início do período de análise (2011).

$$
\left(\begin{array}{l}
F 10 \\
F 20 \\
F 30 \\
F 40 \\
F 50 \\
F 60 \\
\text { F70 } \\
\text { F80 }
\end{array}\right)=\left(\begin{array}{l}
0,052632 \\
0,28655 \\
0,274854 \\
0,128655 \\
0,064327 \\
0,040936 \\
0,064327 \\
0,087719
\end{array}\right)
$$

Fonte: Elaborada pelo autor.

De modo que Fi1 seja o percentual de países na classe i em 2018, e Fit a participação no longo prazo, pode-se observar quais seriam as variaçóes nos percentuais de participação das classes de 2018 para o futuro.

Figura 3 - Variaçóes nos percentuais de participação das classes de 2018 para o futuro.

$$
\left(\begin{array}{l}
F 1 t \\
F 2 t \\
F 3 t \\
F 4 t \\
F 5 t \\
F 6 t \\
F 7 t \\
F 8 t
\end{array}\right)-\left(\begin{array}{l}
F 11 \\
F 21 \\
F 31 \\
F 41 \\
F 51 \\
F 61 \\
F 71 \\
F 81
\end{array}\right)=\left(\begin{array}{l}
0 \\
0 \\
0 \\
0 \\
0 \\
0 \\
0 \\
1,000
\end{array}\right)-\left(\begin{array}{l}
0,048736 \\
0,275944 \\
0,221448 \\
0,094042 \\
-0,14335 \\
-0,29497 \\
-0,1996 \\
0,997745
\end{array}\right)=\left(\begin{array}{l}
-0,04874 \\
-0,27594 \\
-0,22145 \\
-0,09404 \\
0,143351 \\
0,294968 \\
0,199597 \\
0,002255
\end{array}\right)
$$

Fonte: Elaborada pelo autor.

Analisando os resultados obtidos, através das matrizes de transição de Markov, podemos concluir que até a quinta tentativa os índices de percepção de corrupção não possuem convergência. Entretanto, a partir da quinta tentativa, os índices começam a convergir, principalmente para os grupos das classes 5, 6 e 7. Dessa forma, obtém-se sua convergência máxima na décima tentativa, consolidando assim os resultados.

Desde o início da criação do ranking de percepção de corrupção, elaborado pelo Banco Mundial e a Transparência Internacional, destacam-se Nova Zelândia, Dinamarca e Finlândia, sendo estes, países que figuram nas primeiras posiçóes, em especial, Nova Zelândia e Dinamarca, que se alteram entre primeiro e segundo lugar ao longo dos anos como os países com os menores índices de corrupção no mundo.

Os países que se encontram nas últimas colocaçóes do ranking ao longo dos anos são: Somália, Sudão do Sul, Myanmar e Coréia do Norte. Os países que fazem parte do continente africano, (Somália e Sudão do Sul), possuem economias pequenas e ambas tiveram sua situação econômica gravemente afetada por guerras civis, e que dentre as consequências 
desses acontecimentos, um altíssimo nível de corrupção está entre essas consequências. Já os países do continente asiático (Myanmar e Coréia do Norte), são países que possuem pouca ou nenhuma liberdade econômica, restrito acesso à informação sobre os gastos públicos e sistemas políticos ditatoriais por longos períodos, formando práticas propícias para um alto nível de corrupção.

Analisando especificamente o Brasil, percebe-se que o país, ao longo dos últimos vinte e cinco anos analisados, ocupa uma posição intermediária/baixa no ranking de percepção de corrupção, aparecendo com uma média de 38 pontos. Atualmente, o Brasil ocupa sua pior posição da história no ranking, aparecendo na $105^{\text {a }}$ posição.

\section{CONCLUSÃO}

A corrupção é um problema que atinge as sociedades modernas e colabora para diminuir a eficiência, comprometendo o crescimento econômico e a formação social. Assim, pelo Banco Mundial, a corrupção exige medidas prioritárias, pois uma significativa perda manifesta-se nos setores público e privado, perpetuando pobreza e impedindo a prosperidade de significativas parcelas da sociedade. Em especial, destaca-se que a corrupçáo não necessariamente envolve apenas dimensôes pecuniárias, mas também procedimentos escusos de favorecimentos e relaçóes privilegiadas.

No Brasil, a percepção sobre a prevalência de corrupção piorou nos últimos anos, tanto pelo ponto de vista da populaçáo local, bem como por parte dos atores que lidam com os negócios no nível local. Para a população, a corrupção é aquela manifestação que tira recursos de suas prioridades como Educação, Saúde e Segurança, e sempre que um serviço é mal prestado nessas áreas, a corrupção é invariavelmente citada como causa ou parte da causa.

De outro modo, a economia reconhece a ligação entre os problemas e procura medir o impacto da corrupção nas diversas dimensóes do crescimento econômico, tanto do ponto de vista macroeconômico, quanto do ponto de vista microeconômico.

A abertura comercial, o contato entre sociedades e as trocas culturais, por vezes, podem colaborar para que procedimentos sejam atualizados e homogeneizados, aproximando os padróes até mesmo no caso de ilegalidades e suas eventuais adoçóes, extinçóes e penalidades. Assim, esta monografia analisou se a corrupção percebida entre os países do mundo converge para um padrão único, baixo ou superior, ou alternativamente, se há formação de clusters entre categorias de países, sejam elas geográficas ou de níveis de desenvolvimento.

No presente estudo, foram elaborados 8 classes de percepção de corrupção, de acordo com o nível do índice de percepção de corrupção dos 171 países que fazem parte do ranking elaborado pelo Banco Mundial em parceria com a Transparência Internacional, onde a classe 1 é formada por países com altos índices de corrupção, e a classe 8 é formada por países com baixos índices de corrupção.

Desse modo, aplicando as matrizes de transição de Markov, no período entre $2011 \mathrm{e}$ 2018, obteve-se uma convergência para as classes 5 e 6, respectivamente, sendo estas, faixas intermediárias. 
Assim, se por um lado comprova-se a convergência provável para os índices de corrupção, por outro percebe-se que esta convergência se daria não para as melhores práticas, tal como percebidas hoje, mas antes para práticas consideradas intermediárias. De toda forma, representaria uma evolução significativa para a maioria dos países avaliados, o que colaboraria para amenizar o impacto sobre as economias nacionais.

Algumas hipóteses para haver maior convergência para as classes intermediárias, e não para as classes superiores por exemplo, são: os países que possuem uma maior participação do governo na economia; abertura ou fechamento relativo das economias; processos de enriquecimento rápidos e processo político. Ademais, a convergência para as faixas intermediárias pode ocorrer devido a um maior contato entre as economias, a uma maior similaridade na reprodução de leis e padrôes de comércio.

De tal sorte, trabalhos futuros podem examinar os motivos que poderiam causar a convergência e mesmo determinar o ritmo com a qual ela ocorre entre os países para as faixas determinadas.

\section{REFERÊNCIAS}

ABRAMO, C. W. Relaçóes entre índices de percepção de corrupção e outros indicadores em onze países da América Latina. São Paulo, Cadernos Adenauer, v. 10, 2000.

Disponível em: https://docplayer.com.br/40270472-Relacoes-entre-indices-de-percepcaode-corrupcao-e-outros-indicadores-em-onze-paises-da-america-latina-1.html

ABRAMO, C. W. Percepçóes pantanosas: A dificuldade de medir a corrupçáo. Novos Estudos, São Paulo, n.73, p.33-37, 2005.

AL-MARHUBI, F. Corruption and Inflation. Economics Letter, v. 66, p. 199-202, 2000.

ANDERSON, C.J; TVERDOVA, V. Corruption, Political Allegiances, and Attitudes toward Government in Contemporary Democracies. American Journal of Political Science. p. 91-109. 2003.

BAUNGARTEN, B.; ORELLANA, V. Q.; MENEZES, G. Empreendedorismo e Corrupçáo: Uma análise empírica para países selecionados. Encontro de Economia Gaúcha, 8. Anais...Porto Alegre: Fundação de Economia e Estatística, 2016. Disponível em: http://www.pucrs.br/face/wp-content/uploads/sites/6/2016/03/18_BRUNATEIXEIRA-BAUNGARTEN.pdf

BECKER, G. S. Crime and Punishment: An Economic Approach. Journal of Political Economy, vol 76, n. 2, p. 167-212, 1968.

BUCHANAN, J. M.; TULLOCK, G. Towards a theory os rent-seeking Society, College station, Texas A\&M University Press, 1980. 
CARRARO, A.; FOCHEZZATO, A.; HILLBRECHT, R. O. O impacto da corrupçáo sobre o crescimento econômico do Brasil: aplicaçáo de um modelo de equilíbrio geral para o período 1994-1998. 2006.

CARRARO, A.; DAMÉ, O.M. Educação e corrupção: A busca de uma evidência empírica. UC Berkeley, Latin American and Caribbean Law and Economics Associations. (ALACDE) Annual Pappers, 2007.

CARRARO, A. HILLBRECHT, R.O. Modelos microeconômicos de corrupçáo burocrática e seus determinantes econômicos. Encontro da Associação Nacional de Economia, ANPEC. 2003. Disponível em: http://www.anpec.org.br/encontro2003/ artigos/D36.pdf

CHAVES, A. C. S. A corrupção privada no Brasil. Revista Jurídica da Escola Superior do Ministério Público de Sáo Paulo, v.4, 2014. Disponível em: http://www.esmp.sp.gov. br/revista_esmp/index.php/RJESMPSP/article/view/154

FERNANDES, C.M. Uma análise do índice de percepção de corrupção da Transparência Internacional. 2017, 47 f. Monografia (Graduação em Ciências Econômicas). Universidade Estadual da Grande Dourados, Dourados, 2017.

FERNANDES, D. P.; VARGAS, V. Conceitos e simulaçáo de cadeias de Markov. Relatório de Iniciação Cinetífica, UFG, Goiás, 2006. Disponível em: http://www.sbpcnet. org.br/livro/63ra/conpeex/pivic/trabalhos/DIVALDO_.PDF

FONSECA, A. F. O combate a corrupção sob a perspectiva internacional. TEXTOS\&DEBATES, Boa Vista, n.19, p.31-45, 2011.

GARCIA, R. L. A Economia da Corrupção - Teorias e Evidências - Uma aplicação ao setor de obras rodoviárias no Rio Grande do Sul. 2003 Tese (Doutor em Economia) - Programa de Pós-Graduação em Economia da Faculdade de Ciências Econômicas da Universidade Federal do Rio Grande do Sul. Porto Alegre. 2003.

GUPTA, S.; DAVOODI. H.; ALONSO-TERME, R. Does corruption affect income inequality and poverty? International Monetary Fund Working Paper, n. 98, 1998.

KLEIN, F. A. Corrupção e Economia Subterrânea: Uma análise teórica e empírica. Encontro da Associação Nacional de Pesquisadores em Administração, ENANPAD, 2008. Disponível em: http://www.anpad.org.br/admin/pdf/APS-B646.pdf

LAMBSDORFF, G. J. Corruption in Empirical Research - A Review. 9th International Anti-Corruption Conference, Durban, South Africa, 10-15 December, 1999. 
DE LA TORRE, B.G; CERINA, Giorgio D.M. Sobre la corrupción entre particulares. Convênios internacionales y derecho comparado. Revista Brasileira de Ciências

Criminais, ano 19, n. 89, p. 159-213, 2011.

MAURO, P. Corruption and Growth. Quaterly Journal of Economics, v. 110, n. 3, p. 681-712, 1995.

MAURO, P. Why Worry About Corruption? Economic Issue, n.6. Washington D.C. International Monetary Fund: 1997.

MITCHELL, W; SIMMONS, R. Para Além da Política: Mercados, Bens Estar e o Fracasso da Burocracia. Rio de Janeiro, Top Books, 2003.

MO, P. H. Corruption and Economic Growth. Journal of Comparative Economics. n. 29, p. 66-79. 2000.

PERSSON, T.; G. TABELLINI, G. The Economic Effects of Constitutions. Cambridge, MA: MIT Press, 2003.

QUAH, D. Empirical cross-section dynamics in economic growth. European Economic Review, v.37, p. 426-434, 1993.

QUAH, D. Galton's fallacy and tests of the convergence hypothesis. The Scandinavian Journal os Economics, v.95, p. 427-443, 1993.

ROSE-ACKERMAN, S. The economics of corruption. Journal of Public Economics, v. 4, n. 2, p. 187-203, 1975.

ROSE-ACKERMAN, S. Altruism, Nonprofits, and Economic Theory. Journal of Economic Literature, Vol XXXIV, p. 701-728. 1996.

SCHLEIFER, A.; VISHNY, R. W. Corruption. Quaterly Journal os Economics, v. 107, p. 599-618, 1993.

SILVA, M. F. G.D. A economia política da corrupção no Brasil. São Paulo: Editora Senac, 2001.

SIMON, C. P.; BLUME, L. Matemática para economistas. Porto Alegre: Editora Bookman, 2004.

SOUZA, N. J. Desenvolvimento Econômico. 5. Ed. São Paulo: Atlas, 2005.

SPECK, B. W. et al. Os custos da corrupção. Cadernos Adenauer, n 10, p. 47-62, 2000. São Paulo: Fundação Konrad Adenauer. 
STULP, V. J.; FOCHEZATTO, A. A evolução das disparidades regionais no Rio Grande do Sul: uma aplicação de matrizes de Markov. Nova Economia, Belo Horizonte, MG, v. 14, n. 1, p. 39-66, 2004.

TANZI, V. Corruption, Governmental, Activities, and Markets. IMF Working Paper, 94/99, 1994. Disponível em: https://www.imf.org/en/Publications/WP/ Issues/2016/12/30/Corruption-Governmental-Activities-and-Markets-1912

TANZI, V.; DAVOODI, H. Corruption, Public Investment, and Growth. IMF Working Paper, 97/139, 1997. Disponível em: https://www.imf.org/external/pubs/ft/wp/ wp97139.pdf

TRANSPARÊNCIA INTERNACIONAL. Corrupçáo. 2018. Disponível em https:// transparenciainternacional.org.br/quem-somos/perguntas-frequentes/

TRANSPARENCY INTERNATIONAL. Relatório anual do Índice de Percepçáo de Corrupçáo. 2017. Disponível em https://www.transparency.org/research/cpi/overview TREISMAN, D. The causes of corruption: a cross-national study. Journal of Public Economics, v. 76, p. 399-457, 2000.

WORLD BANK. CPIA transparency, accountability, and corruption in the public sector. Disponível em https://data.worldbank.org/indicator/iq.cpa.tran.xq 